\title{
Temporal trends in weight and current weight-related behaviour of Australian Aboriginal school-aged children
}

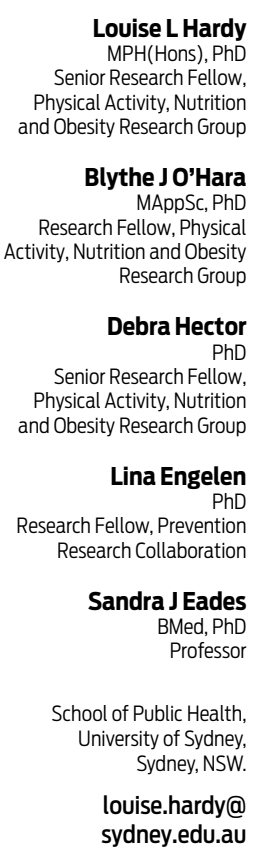

MJA 2014; 200: 667-672 doi: 10.5694/mjal3.10614
T he health status of Australian Aboriginal and Torres Strait Islander (hereafter Aboriginal) children is comparatively poorer than for non-Aboriginal Australian children. ${ }^{1}$ Such health inequalities may be confounded by social disadvantage. However, Aboriginal adults report higher rates of lifestyle behavioural risk factors associated with chronic diseases including obesity, cardiovascular disease and type 2 diabetes. 1 Given the gap in health status experienced by Aboriginal people, there is a need to focus preventive efforts in childhood, adolescence and early adulthood to minimise risks of chronic diseases later in life. 2,3 Accordingly, obtaining representative population data on Aboriginal children's lifestyle behaviour is a priority to understand how best to attenuate chronic disease risk during childhood.

Some evidence suggests that there are no significant differences between school-aged Aboriginal and nonAboriginal children in the prevalence of overweight and obesity.4,5 However, other studies among preschool-aged children show significantly higher rates of overweight and obesity in Aboriginal compared with non-Aboriginal children, ${ }^{6,7}$ suggesting that the new cohort of Aboriginal children entering school may be at higher risk than the current cohort of school-aged children. Evidence of the distribution of weight-related behaviour among Aboriginal children, generated from large representative samples, will help identify priority areas for culturally relevant and appropriate programs.

Our aims were to report temporal trends in weight status of children aged $5-16$ years, by Aboriginality, using representative population health monitoring survey data collected in 1997, 2004 and 2010; and to use the 2010 data to examine differences between Aboriginal and nonAboriginal children's weight and weight-related behaviour.

\section{Abstract}

Objectives: To report 13-year trends in weight status of Australian Aboriginal children, and to describe weight-related behaviour in children in 2010 , by Aboriginality.

Design, setting and participants: Cross-sectional population surveys of children aged 5-16 years $(n=18983)$ conducted in New South Wales schools in Term 1 of 1997, 2004 and 2010.

Main outcome measures: For trend analysis: body mass index and waist-toheight ratio (WtHr). Analyses of weight-related behaviour from 2010 survey data included indicators of dietary habits, screen time (ST) and physical activity.

Results: Between 1997 and 2010, the relative increase in prevalence of overweight/obesity and $\mathrm{WtHr} \geqslant 0.5$ was $22.4 \%$ and $113.6 \%$, respectively, among Aboriginal children, and $11.8 \%$ and $3.4 \%$, respectively, among non-Aboriginal children. In 2010, Aboriginal children had 1.52 (95\% Cl, 1.03-2.24) greater odds of having a WtHr $\geqslant 0.5$ than non-Aboriginal children. Compared with nonAboriginal children, Aboriginal children also had significantly lower odds of eating breakfast daily (adjusted odds ratio [AOR], 0.72; 95\% Cl, 0.52-0.99) and significantly greater odds of drinking $\geqslant 1$ cup of soft drink daily (AOR, 1.61; 95\% Cl, 1.13-2.29), having a television in their bedroom (AOR, 2.75; $95 \% \mathrm{Cl}$, 2.04-3.70), having no ST rules (AOR, 1.34; 95\% Cl, 1.04-1.73) and exceeding ST recommendations on weekdays ( $\mathrm{AOR}, 1.78$; 95\% $\mathrm{Cl}, 1.32-2.39$ ).

Conclusions: Overweight/obesity and $\mathrm{WtHr}$ have increased more rapidly in Aboriginal than non-Aboriginal children in NSW. Unhealthy weight-related behaviour was frequent among all children, but lack of daily breakfast, excessive ST and soft drink consumption appear particularly problematic among Aboriginal children. Raising awareness with families of the consequences of excessive ST and encouraging strategies to limit ST (such as rethinking placement of televisions in children's bedrooms and implementing ST rules) hold promise.

\section{Methods}

This study involved secondary analysis of the New South Wales Schools Physical Activity and Nutrition Survey (SPANS), a representative cross-sectional population surveillance survey of children's weight and weight-related behaviour conducted in $1997(n=5518)$, $2004(n=5407)$ and $2010(n=8058)$. For each survey, schools in NSW were selected at random so that the number of schools selected in each education sector (government, Catholic and independent) was proportional to the number of students enrolled in that sector. The likelihood of a school being selected was proportional to the size of student enrolment. In each school, one class was chosen at random from each of the grades being surveyed. Detailed descriptions of each survey's methodology have been published elsewhere. ${ }^{8}$ Briefly, data were collected in Term 1 (February-April) by teams of trained field staff using standardised protocols for survey consistency. As questions on weight-related behaviour have changed across surveys, only findings from 2010 data are presented here for that analysis.

Informed consent from each child's parent or carer was a requirement for participation. Ethics approval for the study was granted by the University of Sydney Human Research Ethics Committee, the NSW Department of Education and Training and the NSW Catholic Education Commission. The Aboriginal Health and Medical Research Council Ethics Committee approved this publication.

\section{Measures}

On each survey, demographic details included the child's sex, date of birth, postcode of residence and Aboriginality. Postcode of residence was used as a proxy for socioeconomic status (SES), based on the Australian Bureau of Statistics Index of Relative Socio-Economic Disadvantage, and 


\begin{tabular}{|c|c|c|c|c|c|c|c|c|}
\hline & \multicolumn{4}{|c|}{ Aboriginal } & \multicolumn{4}{|c|}{ Non-Aboriginal } \\
\hline & 1997 & 2004 & 2010 & $P$ for trend & 1997 & 2004 & 2010 & $P$ for trend \\
\hline Boys $(n)$ & 74 & 61 & 112 & & 2857 & 2697 & 3971 & \\
\hline Overweight/obese & $20.3 \%$ & $26.2 \%$ & $25.9 \%$ & 0.56 & $19.8 \%$ & $24.21 \%$ & $22.8 \%$ & 0.003 \\
\hline Waist-to-height ratio $\geqslant 0.5$ & $8.3 \%$ & $13.1 \%$ & $16.1 \%$ & 0.52 & $13.2 \%$ & $7.9 \%$ & $12.5 \%$ & $<0.001$ \\
\hline Girls $(n)$ & 65 & 62 & 133 & & 2480 & 2575 & 3636 & \\
\hline Overweight/obese & $27.7 \%$ & $24.2 \%$ & $31.6 \%$ & 0.55 & $20.8 \%$ & $22.6 \%$ & $22.6 \%$ & 0.37 \\
\hline Waist-to-height ratio $\geqslant 0.5$ & $9.3 \%$ & $12.9 \%$ & $21.1 \%$ & 0.13 & $9.8 \%$ & $4.7 \%$ & $11.7 \%$ & $<0.001$ \\
\hline All $(n)$ & 139 & 123 & 245 & & 5337 & 5272 & 7607 & \\
\hline Overweight/obese & $23.7 \%$ & $25.2 \%$ & $29.0 \%$ & 0.52 & $20.3 \%$ & $23.4 \%$ & $22.7 \%$ & 0.004 \\
\hline Waist-to-height ratio $\geqslant 0.5$ & $8.8 \%$ & $13.0 \%$ & $18.8 \%$ & 0.06 & $11.6 \%$ & $6.3 \%$ & $12.0 \%$ & $<0.001$ \\
\hline
\end{tabular}

was used to rank children in tertiles of SES. ${ }^{9}$ Aboriginality was determined by asking "Are you of Aboriginal and/or Torres Strait Islander origin?" (responses: Yes, No, Don't know). Anthropometry was measured and included height $(\mathrm{m})$, weight $(\mathrm{kg})$ and waist circumference (cm). Body mass index (BMI; $\mathrm{kg} / \mathrm{m}^{2}$ ) was calculated, and each student's BMI status was categorised as overweight/obese or not overweight/obese using the International Obesity Task Force age-sex-adjusted cut-points. ${ }^{10}$ Waist-to-height ratio (WtHr), an index of cardiometabolic disease risk, was calculated and categorised as $<0.5$ or $\geqslant 0.5 .11$

\section{Weight-related behaviour}

In 2010, parents of Grade K, 2 and 4 children were sent a questionnaire to complete about their child's weightrelated behaviour, and Grade 6, 8 and 10 children self-completed the same questionnaire at school.

Indicators of dietary quality and habits came from the validated NSW Child Health Survey, which was developed for population-based monitoring, 12,13 and included frequency of consumption of energy-dense, nutrient-poor (EDNP) foods, specifically fried potato products, salty snack products, other snack products, icecream or iceblocks, and fast food. The response categories were: never/rarely, 1-2 times/week, 3-4 times/week, 5-6 times/week, daily, and two or more times/day. As reporting on the frequency of eating individual EDNP foods may obscure the true extent of overall EDNP food consumption among children, a combined summary score was generated from the consumption frequency of each item. The cut-point for high EDNP food consumption was based on the distribution of the data, which showed that more than $50 \%$ of children consumed one or more items three or more times a week. Soft drinks (including cordial and sports drinks) and fruit juice were also assessed (same response categories) and were examined separately as single variables. Additional dietrelated questions included frequency of eating breakfast, frequency of eating dinner in front of the television, and how often good behaviour was rewarded with sweets.

Questions on children's physical activity came from the NSW Population Child Health Survey (for Grades $\mathrm{K} / 2 / 4)^{14}$ and the Adolescent Physical Activity Recall Questionnaire (for Grades 6/8/10). ${ }^{15}$ Responses were used to determine whether children met the physical activity recommendation of $\geqslant 60 \mathrm{~min} /$ day. $^{16}$ Cardiorespiratory endurance (ie, fitness) was assessed among children in Grades 4, 6, 8 and 10 , using the 20-metre shuttle run test,, 17 and children were categorised as "adequately fit" or "unfit" according to published age-sex-adjusted reference cut-points. ${ }^{18}$ Information on recreational screen time (ST) (ie, watching television or DVDs, using a computer for fun, playing electronic games) was assessed using the Adolescent Sedentary Activity Questionnaire ${ }^{19}$ and used to determine whether children met the ST recommendation of $<2$ h/day. ${ }^{16}$ Respondents also reported if there was a television in the child's bedroom and whether there were rules about ST.

\section{Statistical analysis}

Data were analysed in April 2013 using SPSS Complex Samples, version 21 for Windows (IBM), to account for the cluster design of the study and adjust for the standard errors and 95\% confidence intervals. Statistical significance was accepted at $P<0.05$. For the analyses, students were stratified by Aboriginal status as Aboriginal or non-Aboriginal (which included a few who answered "Don't know"). Within SPSS Complex Samples, $\chi^{2}$ tests and tests of independence were used to assess the differences in children's sociodemographic characteristics according to Aboriginality. Logistic regression was used to assess the differences in the proportion of children who were overweight/obese and had WtHr $\geqslant 0.5$ across surveys (1997, 2004 and 2010), stratified by Aboriginality and sex, controlling for SES and grade.

Differences in weight-related behaviour reported in the 2010 survey between Aboriginal and non-Aboriginal children were assessed using logistic regression, controlling for sex, grade and SES.

\section{Results}

Survey response rates for 1997, 2004 and 2010 were $87 \%, 65 \%$ and $57 \%$, respectively. Students were aged 5-16 years. The characteristics of the sample by Aboriginality and survey year are given in the Appendix (online at mja. com.au). About 2\%-3\% of the sample in each survey year identified as Aboriginal and were more likely to live in rural and low-SES areas than their non-Aboriginal peers. 
2 Weight and weight-related behaviour among New South Wales children aged 5-16 years in 2010 survey, by Aboriginality

\begin{tabular}{|c|c|c|c|c|}
\hline & $\begin{array}{l}\text { Aboriginal } \\
\left(n=254^{*}\right)\end{array}$ & $\begin{array}{c}\text { Non-Aboriginal } \\
\left(n=7417^{\dagger}\right)\end{array}$ & $\begin{array}{l}\text { Odds ratio } \\
(95 \% \mathrm{Cl})^{\ddagger}\end{array}$ & $\begin{array}{l}\text { Adjusted odds ratio } \\
(95 \% \mathrm{Cl})^{\neq \S}\end{array}$ \\
\hline \multicolumn{5}{|l|}{ Weight status } \\
\hline Overweight/obese & $29.0 \%$ & $22.7 \%$ & $1.39(1.01-1.92)$ & $1.28(0.92-1.78)$ \\
\hline Waist-to-height ratio $\geqslant 0.5$ & $18.8 \%$ & $12.0 \%$ & $1.69(1.14-2.50)$ & $1.52(1.03-2.24)$ \\
\hline \multicolumn{5}{|l|}{ Dietary habits and behaviour } \\
\hline Meets daily fruit consumption recommendation & $72.4 \%$ & $76.5 \%$ & $0.81(0.55-1.18)$ & $0.80(0.58-1.12)$ \\
\hline Meets daily vegetable consumption recommendation & $38.5 \%$ & $35.4 \%$ & $1.14(0.89-1.49)$ & $1.24(0.95-1.62)$ \\
\hline Eats breakfast every day & $70.0 \%$ & $78.6 \%$ & $0.64(0.47-0.86)$ & $0.72(0.52-0.99)$ \\
\hline Drinks $\geqslant 1$ cup/day of soft drink & $19.8 \%$ & $12.5 \%$ & $1.72(1.20-2.46)$ & $1.61(1.13-2.29)$ \\
\hline Drinks $\geqslant 1$ cup/day of fruit juice & $28.9 \%$ & $27.9 \%$ & $1.05(0.73-1.51)$ & $1.03(0.72-1.46)$ \\
\hline Consumes EDNP foods $\geqslant 3$ times/week & $78.7 \%$ & $76.7 \%$ & $1.12(0.81-1.56)$ & $1.12(0.80-1.55)$ \\
\hline Eats dinner in front of television $\geqslant 3$ times/week & $41.5 \%$ & $34.2 \%$ & $1.37(1.03-1.82)$ & $1.29(0.97-1.72)$ \\
\hline Parents usually/sometimes reward good behaviour with sweets & $59.5 \%$ & $51.1 \%$ & $1.40(1.07-1.84)$ & $1.30(0.99-1.71)$ \\
\hline \multicolumn{5}{|l|}{ Screen time (ST) } \\
\hline Has a television in bedroom & $55.6 \%$ & $29.1 \%$ & $3.04(2.25-4.11)$ & $2.75(2.04-3.70)$ \\
\hline No rules on television and electronic games & $27.9 \%$ & $21.1 \%$ & $1.45(1.06-1.97)$ & $1.34(1.04-1.73)$ \\
\hline Exceeds daily ST recommendation on weekdays & $62.8 \%$ & $47.0 \%$ & $1.90(1.43-2.53)$ & $1.78(1.32-2.39)$ \\
\hline Exceeds daily ST recommendation on weekends & $81.0 \%$ & $82.2 \%$ & $0.92(0.61-1.38)$ & $0.93(0.61-1.41)$ \\
\hline \multicolumn{5}{|l|}{ Physical activity } \\
\hline Grade K/2/4 met daily physical activity recommendation & $45.0 \%$ & $46.6 \%$ & $0.94(0.58-1.52)$ & $1.03(0.61-1.73)$ \\
\hline Grade $6 / 8 / 10$ met daily physical activity recommendation & $61.4 \%$ & $62.0 \%$ & $0.98(0.71-1.34)$ & $1.09(0.78-1.52)$ \\
\hline Competency in locomotor FMS ( $\geqslant 3 / 4$ skills) & $7.1 \%$ & $8.9 \%$ & $0.78(0.49-1.26)$ & $0.83(0.50-1.38)$ \\
\hline Competency in object control FMS ( $\geqslant 2 / 3$ skills) & $19.3 \%$ & $19.3 \%$ & $1.00(0.68-1.47)$ & $1.16(0.72-1.87)$ \\
\hline Adequately fit** & $65.5 \%$ & $68.1 \%$ & 0.89 (0.60-1.32) & $1.09(0.72-1.63)$ \\
\hline
\end{tabular}

EDNP = energy-dense, nutrient-poor. FMS = fundamental movement skills. * Number of Aboriginal children in Grades $\mathrm{K} / 2 / 4=37,30,42$ respectively, and in Grades $6 / 8 / 10=48,59,38$, respectively. $†$ Number of non-Aboriginal children in Grades K/2/4 = 1072, 1191, 1305, respectively, and in Grades 6/8/10 $=1107$, 1473,1269 , respectively. ₹For Aboriginal children compared with non-Aboriginal children. Bold indicates significant values. \$ Adjusted for sex, grade and socioeconomic status. 9 Also includes cordial and sports drinks. **Fitness measured among students in Grades 4, 6, 8 and 10.

Overall, between 1997 and 2010, the relative increase in the prevalence of overweight/obesity and $\mathrm{WtHr}$ $\geqslant 0.5$ was $22.4 \%$ and $113.6 \%$, respectively, among Aboriginal children, and $11.8 \%$ and $3.4 \%$, respectively, among non-Aboriginal children. Trends in the prevalence of overweight/obesity and $\mathrm{WtHr} \geqslant 0.5$ differed according to Aboriginality and sex, after controlling for SES and grade (Box 1). The increase in prevalence of overweight/obesity over time was only statistically significant among non-Aboriginal boys $(P=0.003)$. There was a non-significant increase in the prevalence of overweight/obesity in Aboriginal boys $(P=0.56)$ and girls $(P=0.55)$. The prevalence of $\mathrm{WtHr} \geqslant 0.5$ increased overall, but this was only significant for nonAboriginal children.

Among Aboriginal children, the average annual increase in overweight/obesity between 1997 and 2004 was 0.21 percentage points, and between 2004 and 2010 was 0.63 percentage points. For $\mathrm{WtHr} \geqslant 0.5$, the average annual increases were 0.60 and 0.97 percentage points, respectively. For non-Aboriginal children, overweight/obesity increased 0.44 percentage points annually between 1997 and 2004, but decreased 0.12 percentage points annually between 2004 and 2010. Conversely, WtHr $\geqslant 0.5$ decreased 0.76 percentage points annually between 1997 and 2004 and increased 0.95 percentage points annually between 2004 and 2010 .

In the 2010 survey, there were 254 Aboriginal children (109 in Grades K/2/4; 145 in Grades 6/8/10) and 7417 non-Aboriginal children (3568 in Grades K/2/4; 3849 in Grades 6/8/10). Box 2 shows the prevalence and unadjusted and adjusted odds ratios (AORs) of weight and weight-related behaviour, by Aboriginality, after controlling for sex, grade and SES. Aboriginal children had 1.52 (95\%
CI, 1.03-2.24) greater odds of having a WtHr $\geqslant 0.5$ than non-Aboriginal children. Compared with non-Aboriginal children, Aboriginal children had significantly lower odds of eating breakfast daily (AOR, 0.72; 95\% CI, 0.52-0.99) and significantly greater odds of drinking $\geqslant 1$ cup of soft drink daily (AOR, 1.61; 95\% CI, 1.13-2.29), having a television in their bedroom (AOR, 2.75; 95\% CI, 2.04-3.70), having no ST rules (AOR, 1.34; 95\% CI, 1.041.73) and exceeding ST recommendations on weekdays (AOR, 1.78; 95\% $\mathrm{CI}, 1.32-2.39)$. There were no significant differences between Aboriginal and non-Aboriginal children's physical activity measures, including daily activity, adequate fitness and competency in fundamental movement skills.

\section{Discussion}

This is the first large, representative study to report on temporal trends in 
overweight/obesity and WtHr $\geqslant 0.5$ (an index of cardiometabolic disease risk) among Aboriginal children in NSW. While the increases in prevalence were statistically significant only for non-Aboriginal children, a clear increase in both weight measures across time was also observed in Aboriginal children, and the lack of statistical significance needs to be considered in the context of the small sample of Aboriginal children.

The strengths of our study include the large representative sample of school-aged children and, for weight status, comparability across survey years. Aboriginal children comprised $2 \%-3 \%$ of each survey sample, which approximates the population prevalence of about $5 \%$ of 5-15-year-olds in NSW. ${ }^{20}$ However, the small sample size of Aboriginal children was a limitation, which potentially underpowered our analyses and prevented stratifying the data by individual BMI categories and by sex. Additionally, while the questionnaires were validated, a further limitation was the use of self-report to characterise children's weight-related behaviour.

Despite these limitations, our finding that almost one in three NSW Aboriginal children (29.0\%) aged 5-16 years in 2010 was overweight/ obese is comparable to the prevalence for Aboriginal children of a similar age in a national study conducted in $2006 .{ }^{21}$ Nearly one in five $(18.8 \%)$ had WtHr $\geqslant 0.5$ which, compared with non-Aboriginal children, equated to $52 \%$ higher odds of central adiposity, which is associated with cardiometabolic ill health. In Aboriginal children, waist circumference has been strongly associated with the metabolic syndrome, ${ }^{22}$ but the WtHr is considered a potentially superior indicator of cardiovascular risk clustering in young people ${ }^{23}$ and may be a more appropriate index of adiposity in Aboriginal children. However, the body habitus of Aboriginal children, where the limb-to-trunk ratio differs from nonAboriginal children, ${ }^{24}$ may influence the 0.5 cut-point. Further research is required to ascertain the sensitivity of this cut-point in Aboriginal children. Given there is strong evidence that childhood obesity leads to adult obesity and related comorbidities, 25 and behaviour including sedentariness and physical activity track into adulthood, ${ }^{26,27}$ child obesity prevention programs must be prioritised.

Overall, there were no differences between Aboriginal and non-Aboriginal children in physical activity measures, with less than half of all Grade $\mathrm{K} / 2 / 4$ children and two-thirds of Grade 6/8/10 children meeting daily physical activity recommendations. Few children were competent in fundamental movement skills and a third were deemed unfit. Parental modelling and support are important influences, but schools are a key setting for promoting children's physical activity through the health and physical education (HPE) and school sport programs. While NSW primary schools have programs that promote healthy eating and physical activity (eg, Live LifeWell @ School), a significant policy gap in Australia is the lack of specialised teachers to deliver HPE in primary schools, disadvantaging all children.

We found some similarities in children's dietary patterns independent of Aboriginality, including the overconsumption of EDNP food, parental rewarding of good behaviour with sweets, and low vegetable intake. Interestingly, the dietary differences according to Aboriginality in our study are congruent with those from a study based on 24-hour recalls of food intake. ${ }^{28}$ Around a quarter of children in our study reported not eating breakfast daily, but this was more prevalent among Aboriginal children, who were also more likely to drink soft drink every day than their non-Aboriginal peers. The adjusted model showed that SES and rurality were confounders of daily breakfast and soft drink consumption, and our sample showed that the Aboriginal children were significantly more likely to be from rural and lower SES areas. Although breakfast programs are run in some NSW schools, our findings indicate that many children are not eating breakfast daily, which suggests these programs may not have the necessary reach into disadvantaged groups, including Aboriginal communities.

Soft drinks are associated with a range of morbidities including obesity, diabetes and dental caries. ${ }^{29}$ Both the school and home environments provide key opportunities for children to access soft drinks. ${ }^{30}$ A public education campaign would need to target these two environments, aimed at increasing parental awareness of the need to reduce soft drink availability in the home and to encourage schools to implement mandatory policies banning the sale of sugarsweetened beverages. ${ }^{31}$ Reintroducing campaigns promoting water as the drink of first choice would also be of benefit, as these have been shown to be effective at increasing awareness of water-related nutrition and reducing consumption of soft drinks among children. ${ }^{32}$ Ensuring culturally appropriate school programs, such as Thumbs Up! (run under the auspices of the Jimmy Little Foundation), is one strategy to encourage young Aboriginal Australians to make better and healthier food choices.

The main difference in weightrelated behaviour according to Aboriginality that we found was in ST. Over half of Aboriginal children had a television in their bedroom, a third had no ST rules, and almost two-thirds exceeded the daily ST recommendation on weekdays. While televisions are ubiquitous in most homes, research shows that high ST and televisions in the bedroom are associated with a range of adverse health outcomes including poor diet quality, lower prevalence of regular family meals, sleep disturbances and overweight and obesity. ${ }^{33}$ General community awareness of the negative aspects of ST is low, ${ }^{34}$ and given the higher weekday ST among Aboriginal children, alternative active after-school entertainment options, such as the Active AfterSchool Communities Program, may hold promise in Aboriginal communities. However, such programs must be culturally relevant and engaging.

Acknowledgements: This study was funded by the NSW Ministry of Health. We are grateful for the support and cooperation of the government, Catholic and independent education systems and for the cooperation of the participating schools and students.

Competing interests: No relevant disclosures.

Received 08 May 2013, accepted 04 Mar 2014.

1 Centre for Epidemiology and Evidence. The health of Aboriginal people of NSW: report of the Chief Health Officer, 2012. Sydney: NSW Ministry of Health, 2012. http://www. health.nsw.gov.au/publications/Publications/ Aboriginal-Health-CHO-report.pdf (accessed Mar 2014).

2 Daniels SR, Pratt CA, Hayman LL. Reduction of risk for cardiovascular disease in children and adolescents. Circulation 2011; 124: 1673-1686.

3 National Health and Medical Research Council. The NHMRC Road Map Il: a strategic framework for improving the health of Aboriginal and Torres Strait Islander people through research. 
Canberra: NHMRC, 2010. http://www. nhmrc.gov.au/files_nhmrc/publications/ attachments/r47.pdf (accessed Mar 2014).

4 Cinelli RL, O'Dea JA. Body image and obesity among Australian adolescents from indigenous and Anglo-European backgrounds: implications for health promotion and obesity prevention among Aboriginal youth. Health Educ Res 2009: 24: 1059-1068.

5 Haysom L, Williams RE, Hodson EM, et al. Cardiovascular risk factors in Australian indigenous and non-indigenous children: a population-based study. J Paediatr Child Health 2009; 45: 20-27.

6 Spurrier NJ, Volkmer RE, Abdallah CA, et al. South Australian four-year-old Aboriginal children: residence and socioeconomic status influence weight. Aust NZ J Public Health 2012; 36: $285-290$

7 Wolfenden L, Hardy LL, Wiggers J, et al. Prevalence and socio-demographic associations of overweight and obesity among children attending childcare services in rural and regional Australia. Nutr Diet 2011; 68: 15-20.

8 Hardy LL, King L, Espinel P, et al. Methods of the NSW Schools Physical Activity and Nutrition Survey 2010 (SPANS 2010). J Sci Med Sport 2011; 14: 390-396.

9 Australian Bureau of Statistics. Census of Population and Housing: Socio-Economic Indexes for Areas (SEIFA), Australia - Data only, 2006. Canberra: ABS, 2008. (ABS Cat. No. 2033.0.55.001.) http://www.abs.gov.au/ AUSSTATS/abs@.nsf/DetailsPage/2033.0.55.0 012006?OpenDocument (accessed Feb 2010).

10 Cole TJ, Bellizzi MC, Flegal KM, Dietz WH. Establishing a standard definition for child overweight and obesity worldwide: international survey. BMJ 2000; 320: 1240-1243.

11 Browning LM, Hsieh SD, Ashwell M. A systematic review of waist-to-height ratio as a screening tool for the prediction of cardiovascular disease and diabetes: 0.5 could be a suitable global boundary value. Nutr Res $\operatorname{Rev} 2010 ; 23: 247-269$.

12 Flood V, Webb K, Rangan A. Recommendations for short questions to assess food consumption in children for the NSW Health Surveys. Sydney: NSW Centre for Public Health Nutrition, 2005.

13 Flood VM, Wen LM, Hardy LL, et al. Reliability and validity of a short FFQ for assessing the dietary habits of 2-5-year-old children, Sydney, Australia. Public Health Nutr 2014; 17: 498-509.

14 Centre for Epidemiology and Research. New South Wales Population Health Survey: 2005-2006 report on child health. Sydney: NSW Department of Health, 2008. http:// www0.health.nsw.gov.au/pubs/2008/pdf/ childreport0506.pdf (accessed Mar 2014).

15 Booth ML, Okely AD, Chey TN, Bauman A. The reliability and validity of the Adolescent Physical Activity Recall Questionnaire. Med Sc Sports Exerc 2002: 34: 1986-1995.

16 Department of Health. Australia's physical activity and sedentary behaviour guidelines. Canberra: Commonwealth of Australia, 2014 http://www.health.gov.au/internet/main/ publishing.nsf/Content/health-pubhlthstrateg-phys-act-guidelines (accessed May 2014).

17 Léger LA, Lambert J. A maximal multistage 20-m shuttle run test to predict V02 max. Eur J Appl Physiol Occup Physiol 1982; 49: 1-12.

18 Welk GJ, Meredith MD, editors. Fitnessgram/ Activitygram reference guide. 3rd ed. Dallas: The Cooper Institute, 2008.

19 Hardy LL, Booth ML, Okely AD. The reliability of the Adolescent Sedentary Activity Questionnaire (ASAQ). Prev Med 2007; 45: 71-74.

20 NSW Commission for Children and Young People. A picture of NSW children. Chapter Diversity of NSW children. http://picture.kids. nsw.gov.au/demographic/Diversity-of-NSWChildren (accessed Mar 2014)

21 O'Dea JA. Gender, ethnicity, culture and social class influences on childhood obesity among Australian schoolchildren: implications for treatment, prevention and community education. Health Soc Care Community 2008; 16: 282-290.

22 Sellers EA, Singh GR, Sayers SM. Large waist but low body mass index: the metabolic syndrome in Australian Aboriginal children. J Pediatr 2008; 153: 222-227.
23 Garnett SP, Baur LA, Cowell CT. Waist-to-height ratio: a simple option for determining excess entral adiposity in young people. Int J Obes (Lond) 2008; 32: 1028-1030

24 Norgan NG. Interpretation of low body mass indices: Australian Aborigines. Am J Phys Anthropol 1994; 94: 229-237.

25 Serdula MK, Ivery D, Coates RJ, et al. Do obese children become obese adults? A review of the literature. Prev Med 1993; 22: 167-177.

26 Biddle SJ, Pearson N, Ross GM, Braithwaite R. Tracking of sedentary behaviours of young people: a systematic review. Prev Med 2010; 51 : 345-351.

27 Telama R, Yang X, Viikari J, et al. Physical activity from childhood to adulthood: a 21-year tracking study. Am J Prev Med 2005; 28: 267-273.

28 Gwynn JD, Flood VM, D'Este CA, et al. Poor food and nutrient intake among Indigenous and non-Indigenous rural Australian children. BMC Pediatr 2012; 12: 12

29 Brownell KD, Farley T, Willett WC, et al. The public health and economic benefits of taxing sugar-sweetened beverages. N Engl J Med 2009; 361: 1599-1605.

30 Hebden L, Hector D, Hardy LL, King L. A fizzy environment: availability and consumption of sugar-sweetened beverages among school students. Prev Med 2013; 56: 416-418.

31 NSW Ministry of Health. Sugar sweetened drink ban for NSW schools [fact sheet]. Sydney: NSW Health, 2006. http://www0.health.nsw.gov. au/pubs/2006/softdrink_ban.html (accessed Feb 2014).

32 Orr N, Milat AJ, Lin M, et al. Evaluation of the 2008 NSW water campaign. Health Promot J Austr 2010; 21: 114-119.

33 Staiano AE, Harrington DM, Broyles ST, et al. Television, adiposity, and cardiometabolic risk in children and adolescents. Am J Prev Med 2013; 44: 40-47.

34 Hardy LL, King L, Espinel P, et al. NSW Schools Physical Activity and Nutrition Survey (SPANS) 2010: full report. Sydney: NSW Ministry of Health, 2011. http://sydney.edu.au/ medicine/public-health/panorg/pdfs/SPANS FullReport_2010.pdf (accessed Mar 2014).

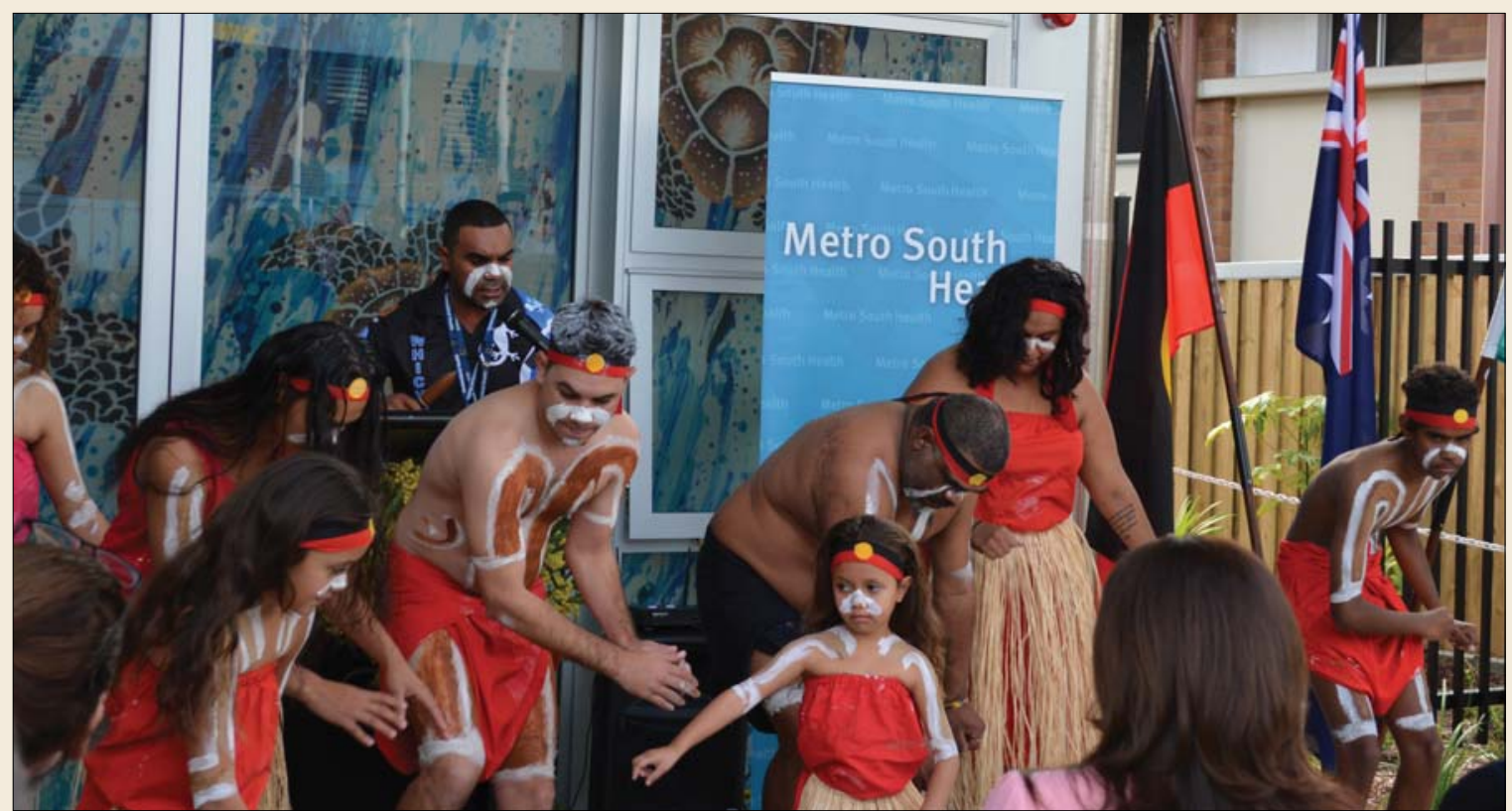

Opening of the Southern Queensland Centre of Excellence in Aboriginal and Torres Strait Islander Primary Health Care, page 623 (Courtesy of Southern Qld Centre of Excellence for Aboriginal and Torres Strait Islander Primary Health Care) 